\title{
Experience of Neuropsychological Treatment of a Patient With Aphasia
}

\author{
Luis Quintanar Rojas, Yulia Solovieva, Arturo López Cortés \\ Autonomous University of Puebla, Puebla, Mexico
}

\begin{abstract}
Consideration of functions and its localization has an impact on the treatment of patients with brain injury. The aim of the article is to show an experience of neuropsychological treatment applied to a Spanish-speaking masculine of 77 years old with brain injury of ischemic type in left anterior artery. Pre- and post-assessment was applied to the patient. The previous assessment established motor efferent aphasia with serious problems of cortical and sub-cortical activation. The program for rehabilitation included special activities on concrete, perceptual, and verbal level of verbal and non-verbal activities. The 11 months of application of program of rehabilitation permitted to obtain considerably better results in all neuropsychological tasks. Functional reorganization in motor organization, oral language, comprehension, drawing, writing, reading, and problem-solving significant for patient's life and occupation took place. Our study shows that the program of neurorehabilitation should be based on qualitative analysis of verbal and non-verbal activity. The results confirm the necessity of inclusion of broad scale of activities during rehabilitation of patients with motor aphasia.
\end{abstract}

Keywords: aphasia, rehabilitation, neuropsychological rehabilitation, cognitive rehabilitation, rehabilitation of aphasia

\section{Introduction}

In the history of neuropsychology, the issue of rehabilitation of patients with brain injury has been associated with two main concepts: How psychological functions are conceived and the localization of the brain injury.

Since the beginnings of neuropsychology, researchers in the field of aphasia have only considered the expressive and receptive language alterations, related to the classic zones of the language (Dejerine, 1926): the Broca zone and the Wernicke zone respectively, proposing these as the material substrate of each one of these processes (Benson \& Ardila, 1996; Ardila, 2005).

Many authors (Goodglass, 1992; Balasubramanian, 2005) have contributed to analyze the specific errors in all forms of oral language associated with particular kind of aphasia. When the patient presents any other difficulties, these are interpreted as "associated alterations”, i.e., in the cases of patients who, besides language problems, present oral and written problems, the diagnosis might be motor aphasia with alexia or agraphia (Goodglass \& Kaplan, 1972; LaPointe, 2005).

Luis Quintanar Rojas, Ph.D., director of Neuropsychology Masters Program, Autonomous University of Puebla. Yulia Solovieva, Ph.D., researcher of Neuropsychology Masters Program, Autonomous University of Puebla. Arturo López Cortés, M.C., researcher of Neuropsychology Masters Program, Autonomous University of Puebla. 
This interpretation shows that in the cases of aphasia, the alteration of others psychological functions are considered in an isolated way, without being related to the language alterations. This form of diagnosis has an impact on the patient's treatment since the proposed rehabilitation methods, behavioral or cognitive, and usually addressed to the symptom (LaPointe, 1977; Seron \& Partz, 1993; Goodglass, 1987; Seron \& Partz, 1993; Cuetos, 1998; Lorenzo \& Fontán, 2001), or to the patient's adaptation to his illness (Gardner, Zurif, Berry, \& Baker, 1976). Alternatively, general treatments for diverse types of aphasia are used (Ojeda del Pozo, Ezquerra-Iribarren, Urruticoechea-Sarriegui, Quemada-Ubis, \& Muños-Céspedes, 2000; Levine et al., 2000; Cuetos, 2004).

In the practice of neuropsychological treatment of patients with aphasia, two basic problems can be considered: treatment of verbal and of non-verbal functions. According to conceptions of localization of functions, the deficits of patients depend on localization of brain injury, which may affect only verbal or only non-verbal processes (Ardila, 2005). Such isolated consideration of functions has an impact on the patient's treatment since the proposed rehabilitation methods, behavioral or cognitive (Seron \& Partz, 1993; Cuetos, 1998; Lorenzo \& Fontán, 2001). General treatments for diverse types of aphasia are commonly used (Cuetos, 2004).

We consider that the neuropsychological assessment and treatment should not be limited either to verbal or non-verbal functions. The conception of dynamic and systemic localization of psychological functions in human brain pretends to find common brain mechanisms for different functions (Tsvetkova, 2000). This means that each brain injury produces a systemic effect in the patient's psychological functions and affects necessarily both verbal and non-verbal processes. According to this conception, the objective of neuropsychological assessment is to establish the systemic effect of brain injury for psychological activity as a whole and to design a specific rehabilitation program. The ultimate goal of rehabilitation should be, besides the overcoming specific difficulties, the recuperation of general cognitive abilities and the reintegration of the patient to his social, familiar, and labor environment (Wilson, 2000; Akhutina, 2002a, 2002b).

To carry out the work of assessment, diagnosis, and rehabilitation of Spanish-speaking patients, our group has incorporated the concepts of neuropsychology developed by Luria (1977) and Tsvetkova (1985; 2000; 2001). Based on this approach, none of the functions (language, reading, writing, etc.) is located in a restricted area of the brain. Any action or function requires the participation of a diverse number of brain zones, which contribute with their specific work. An action or function is through the activation of neuronal populations organized spatially and temporarily. These systems are composed of different "neuropsychological factors" like mechanisms of work, or functioning of zones, or groups of cerebral zones denominated functional systems (Luria, 1977, 1973; Xomskaya, 2002). According to this functional organization, an injury does no affect only one function, but all those functions or actions that require the specific work accomplished by the affected cerebral zone.

From this perspective, the goal of neuropsychological assessment is to identify the affected factor or factors responsible for the difficulties that the patient undergoes.

Thus, the alteration of each factor produces a specific type of aphasia that in this context must be understood not only as an isolated alteration of language, but as a complex neuropsychological syndrome in which other processes are altered, such as memory, thought, writing, attention, calculation, and reading.

We use classification of aphasia proposed by Luria (1977), its brain mechanisms or factors have been studied and elaborated recently (Tsvetkova, 1995; Tsvetkova \& Torchua, 1997; Akhutina, 1989, 2002; 
Quintanar \& Solovieva, 2002; Quintanar, Solovieva, \& León-Carrión, 2002; Solovieva \& Quintanar, 2005). In his classification of aphasia, Luria (1977) proposed to consider four different levels: anatomic, psycho-physiological or neuropsychological, psychological, and linguistic. Table 1 represents these levels for the case of motor efferent aphasia.

Table 1

Affected Levels in Motor Efferent Aphasia

\begin{tabular}{|l|l|l|l|}
\hline Anatomic & Neuropsychological & Psychological & Linguistic \\
\hline $\begin{array}{l}\text { Premotor zones of left } \\
\text { hemisphere }\end{array}$ & $\begin{array}{l}\text { Motor sequential organization } \\
\text { of movements and actions }\end{array}$ & $\begin{array}{l}\text { All actions which require } \\
\text { motor organization (motor } \\
\text { praxis, speaking, writing, } \\
\text { drawing, reading, etc.) }\end{array}$ & $\begin{array}{l}\text { Syntactic operations in } \\
\text { language production and } \\
\text { comprehension }\end{array}$ \\
\hline
\end{tabular}

The neuropsychological factor "sequential motor organization", which is located at the base of the efferent motor aphasia, conduces not only to impossibility of language production. However, the verbal level is only one of the levels of human actions, it is necessary to identify how they affect reading, writing, drawing, and other actions, which require the organization of sequential movements. The involvement of the organization of sequential movements produced by brain damage in the premotor area (frontal posterior zones of left hemisphere) leads to difficulties in all forms of language: spontaneous language, denomination, repetition, syntactic organization of phrases, sentences and texts, silent and loud reading, and all types of writing and drawing. Execution of all kinds of motor dynamic praxis (movements) is also severely affected. Therefore, an injury in these cerebral sectors will affect not only the production of the oral language, but a large specter of actions of a patient. This kind of analysis allows us to point out that in motor efferent aphasia, as in other types of aphasia, multiple difficulties could be explained from the viewpoint of the affected mechanism.

The objective of this study is to show the effectiveness of the application of a neuropsychological rehabilitation program in the case of an adult patient with motor efferent aphasia as consequence of vascular stroke. This study analyzed the results of neuropsychological assessment before and after application of the rehabilitation program.

\section{Case}

This is the case of a 77-year-old male patient (JL), with education level corresponding to completed primary school (six years), right-handed, and trading occupation. He showed symptoms of weakness in legs and arms and temporal loss of orientation. The neurological report showed the presence of right hemiparesis with ipsilateral Babinsky and aphasia as consequence of cerebral ischemia in the area of the anterior cerebral artery.

\section{Instruments}

Brief neuropsychological evaluation for adults (Quintanar \& Solovieva, 2002) and neuropsychological clinical diagnosis of aphasia (Quintanar, Solovieva, \& León-Carrión, 2002) were used for the initial and final evaluation. These instruments assess the functional state of the neuropsychological factors.

\section{Results of Initial Assessment}

The neuropsychological evaluation showed the conservation of the following factors: (1) phonematic; (2) kinaesthetic; and (3) spatial integration. The patient's language was nonfluent with a verbal production was limited to a few words (“Joaquin... Joaquin, Martha... Martha”) which he pronounced persistently as an answer 
to any kind of question. Sometimes, he included words taken from the questions of the evaluator. The patient was completely unable to fulfil the task of reciprocal coordination of the hands, and it was impossible to fulfil for the patient, even with the help of the evaluator's instructions. The same negative result was found in the task of copying a graphical sequence and of a house.

The repetition of series of words and their evocation with homogenous and heterogeneous interference (audio-verbal retention) was impossible due to the presence of stereotypes. The same difficulties were observed in the tasks of visual retention, with presence of perseverations and loss of the activity's objective (see Figure 1). The task consisted in copy of the model and later reproduction after homogeneous interference of three complex figures. During the assessment sessions, the tone of cortical activity diminished as time went by, increasing the number of errors and stereotyped answers.

(1) Model for copy
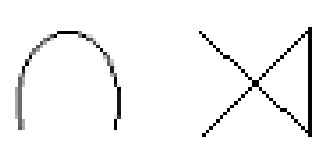

(2) Reproduction
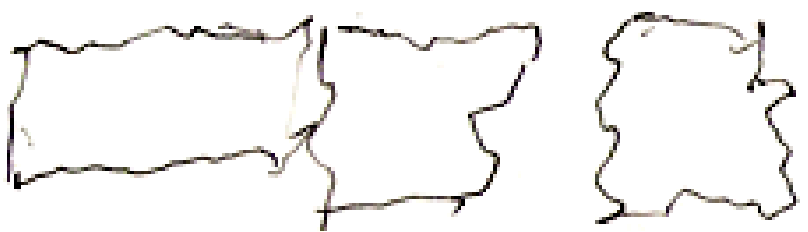

Figure 1. Fulfillment of the task "reproduction of three figures” in initial evaluation.

Table 2

Preserved and Disturbed Brain Mechanisms in Our Patient During Initial Assessment

\begin{tabular}{|l|l|}
\hline Brain mechanism & Preserved or disturbed \\
\hline Kinesthetic analysis and synthesis & No difficulties \\
\hline Phonematic analysis and synthesis & No difficulties \\
\hline Motor sequential organization & $\begin{array}{l}\text { Constant perseveration on verbal and non-verbal levels, absence of productive } \\
\text { independent language, echolalia: Joaquín...Joaquín, Martha....Martha, Martha... }\end{array}$ \\
\hline Visuo-verbal retention & Severe perseveration on graphic and verbal oral level \\
\hline Acustic-amnestic & $\begin{array}{l}\text { Severe perseveration on verbal level instead of nomination of all categories of } \\
\text { words (verbs, nouns, adjectives, and so on) }\end{array}$ \\
\hline Dynamic organization & Absence of independent verbal production, constant perseverations \\
\hline Spatial analysis and synthesis & $\begin{array}{l}\text { Difficulties for comprehension and production of complex grammar structures } \\
\text { (with prepositions and conjunctions of all types) }\end{array}$ \\
\hline
\end{tabular}

These results indicate the presence of a disturbance of the motor sequential organization, which depends on the inferior frontal posterior regions of the left hemisphere (area 44, according to Brodmann). The work done by this cortical zone guarantees the passage of an articulatory movement to another. For this reason, brain lesion in this zone makes it difficult or impossible to produce the sequence of sounds that forms words, phrases, and sentences. Instead, we find the presence of constant multiple perseverations in all kinds of verbal production of the patient (Luria, 1980; Akhutina, 1989). The alteration of this factor produces disturbances not only of diverse forms of language (spontaneous, repetitive, comprehensive, and written), but also of other non-verbal activities (arithmetical operations and graphical activities). This clinical case corresponds to the 
motor efferent aphasia. Table 2 shows functional state of brain mechanisms in our patient during initial assessment.

\section{Program of Neuropsychological Treatment}

The program of neuropsychological treatment was oriented to the formation of the patient's active oral and written language and to the reestablishment of the possibility of regulation of the activity of the patient with the help of his own oral and internal language. The main goals of rehabilitation program we included are:

(1) To overcome pathological inertia at different levels (material, perceptive, and verbal);

(2) To reestablish motor organization (in verbal and non-verbal acts);

(3) To support oral and written production and comprehension.

We applied the rehabilitation program during a period of 11 months, three times per week. Below, we describe the most important exercises of the program organized by stages.

\section{Stage I: Unblocking of Activity and Overcoming of Pathological Inertia}

Part 1: Material and materialized (symbolic material) level. This stage objective was to overcome the perseverations and stereotypes that obstruct the verbal activity of the patient. These tasks reinforced the patient's previous experience with linguistic elements. Exercises and games for general activation were used (categorization and classification of real objects in different colors, sizes and shapes as well as songs and rhymes). One of the most important exercises was the elaboration of material and materialized sequences according to an established model: sequences with geometric shapes, numbers or real objects (see example 1 in Figure 2). Example of such sequences: one square, two circles, one square, two circles and so on; then in different order: two squares, one circle, two squares, one circle and so on.

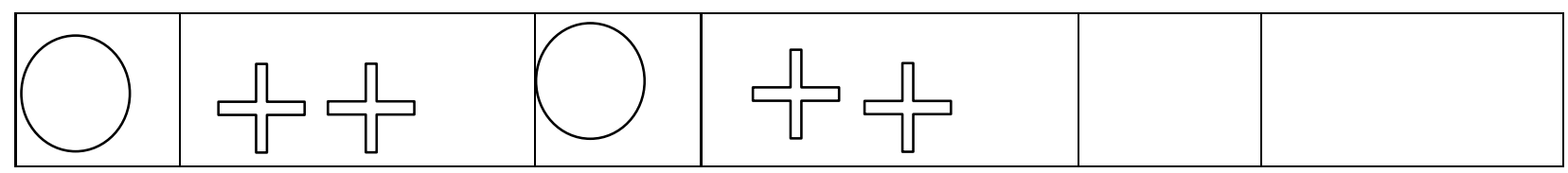

Figure 2. Example 1: Model of materialized sequences.

Part 2: Perceptive level. The categorization and classification of photos and cards with representation of real objects was used at this stage. The sequences were applied at a graphic level, that is to say, the patient had to draw the sequences he had constructed in the previous stage.

\section{Stage II: Reconstruction of Motor Organization}

Part 1: Material and materialized (symbolic material) level. At this stage, the patient worked with numerical material. The Shultz's method of tables was used. The patient's task was to fill in the blank with numbers from 1 to 10 without any order, as he liked. After that, following the instruction of a therapist, he performed the following: show the number in direct, indirect order, without any order, only even numbers and only uneven numbers. The same kinds of exercises were used in the modality of dictation and graphic representation of tables and numbers.

In another exercise, patient listened to a phrase pronounced by the therapist and chose the corresponding picture without pronouncing it compulsorily. The patient pointed to the image that completes the sentence. If the patient considers that the word that correctly completes the sentence is not represented, he could point to the blank square. The therapist always helped and congratulated the patient when he tried to say the corresponding word or if the word came out spontaneously (see example 2 in Figure 3). 

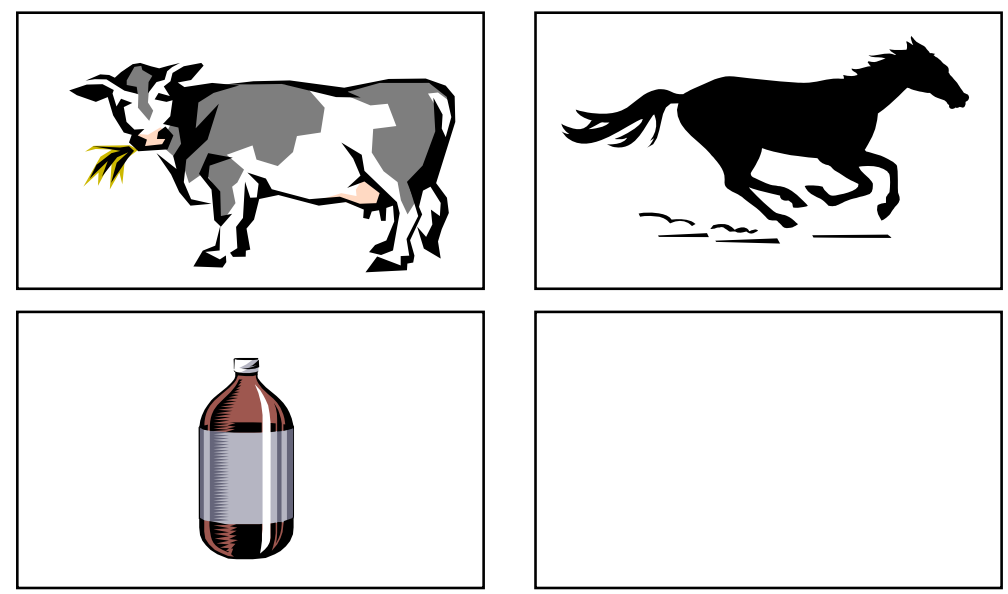

Figure 3. Example 2: Complete the sentences with the card.

Instruction: Listen carefully to the phrase and show an object: "The horse is black", and "The milk of the cow tastes good".

Working with these exercises, the patient spontaneously managed to express names of numbers and other objects.

Part 2: Verbal level. At this stage of rehabilitation, the patient started to pronounce some common words and phrases correctly. With the purpose of guaranteeing a better word production, we used some exercises at the verbal level. Always with the oral help of the therapist, the patient listened to the phrase and completed it with the appropriate word. We used the same exercises (or some very similar ones) as those of the previous stage, with the only difference that this time the patient tried to pronounce the word or even the whole phrase (always helped and encouraged by the therapist).

Also in this stage we worked with rhymes and automatic verbal series (days of the week, numbers, months, names of relatives, etc.). The patient was encouraged to use all these names more frequently in his own speech production. The first stage was worked with word pronunciation through rhymes and rhythms, the evocation of frequent words and with the writing of automatic words like numbers, names of relatives, days of the week, months, etc..

\section{Stage III: Oral and Writing Language}

Part 1: Level of phrases and sentences. Different kinds of photos and cards representing diverse situations were used. The patient listened to a sentence pronounced by the therapist and pointed out the corresponding object, detail, or situation in the photos. He also tried to repeat or complete the phrase, assisted by the therapist. First, we worked on the copy of examples and their evocation. In order to do that, descriptions of the activities fulfilled by the patient the day before were used. Later on, for verb actualization, a phrase was presented to the patient where he had to identify the verb by underlining it with two lines. Afterwards, the verb was covered with a card and the patient had to choose a new verb from a list, place it in the phrase, and read the sentence aloud. Thematic illustrations were used as support. Finally, the patient evaluated the congruency of the sentence produced. This task was used to demonstrate to the patient that is possible to build sentences using different verbs for the same subject (Quintanar \& Cols, 2002).

While working with the elaboration of phrases and sentences, the schemes for symbolic representation of sentences were used. This scheme helped the patient to actualize his internal representation of the phrase or 
sentence by symbolizing the main grammar elements of the phrase: subject and predicate. Such schemes were useful for finding the necessary noun or verb to complete the sentence according to the card or picture.

Scheme of the sentence:

$\begin{array}{rr}\text { Subject (noun) } & \text { Mamá (Mother) } \\ \text { Predicate (verb) } & \text { come (eats) }\end{array}$

The work with phrases instead of isolated words or the denomination of an object helps to prevent syntactic problems, which are very typical in cases of motor efferent aphasia.

In order to reestablish the process of writing, special exercises were used. In the case of writing of words, it was also necessary to guarantee a correct representation of phonetic structure of words and also of the sequence of sound and letters in oral and written words. The method of materialized analysis of the structure of sounds and letter in the words was applied. We call this method as phonetic analysis of the words, which consists of the introduction of an external scheme of the word (Solovieva, Chávez, Pérez, \& Quintanar, 2001; Solovieva \& Quintanar, 2005a, 2005b). Each square of the scheme represents a sound in a concrete word (see example 3 in Figure 4). Such representation of the phonetic structure of the word helped the patient to precise the articulation and the sequence of the sound in the word. The procedure is the following: The therapist pronounces each sound and the patient points the corresponding place in the scheme. In order to favor the sequential dynamic organization of the perception and the articulation of the words, the sound can be pronounced following the original order or not. The patient needed seven sessions to stabilize his writing of words.

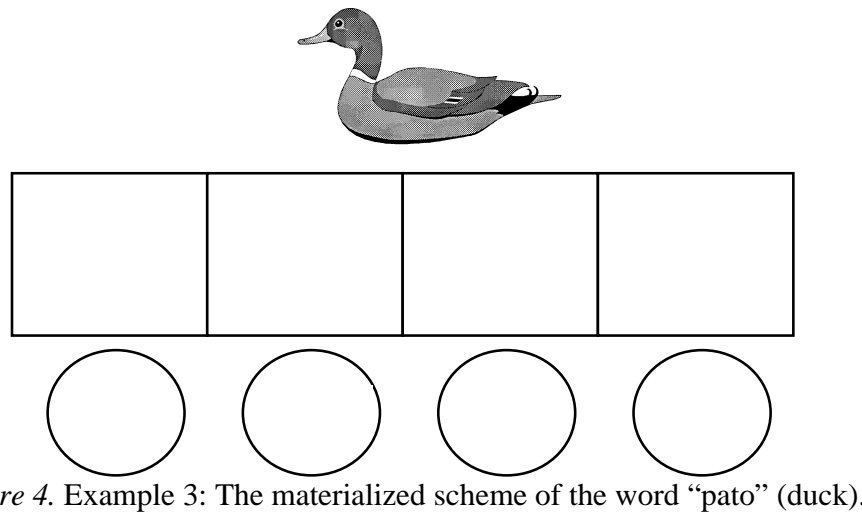

Part 2: Writing of phrases and sentences. Tasks such as copying, writing from memory, and dictation of elaborated phrases and sentences were used.

Verb conjugation exercises were also used (Quintanar \& Cols., 2002). Below, we show some examples of such exercises:

(1) A picture representing an action is presented to the patient;

(2) The therapist describes the picture orally;

(3) The patient is asked to make his own sentence according to the scheme for expressing the situation shown in the picture;

(4) The patient is asked to write the sentence or to copy it in case of difficulties;

(5) The patient is asked to verify and correct the execution, if necessary;

(6) The patient is asked to read the sentence with the therapist's help; 
(7) The therapist hides the scheme and asks the patient to say a sentence without the support of the scheme;

(8) The same sentence is changed into the simple past tense and the same procedure is applied;

(9) The same sentence is changed into the simple future tense and the same procedure is applied;

(10) It is possible to try to use the other grammar tenses.

Part 3: Actualization of independent grammar categories. In this stage, we used the exercises for rehabilitation of grammar categories. The objective of these exercises was to overcome and to anticipate pathological syntactic difficulties called "telegraphic style":

(1) The therapist shows an object to the patient (an apple) explaining that it is a noun;

(2) The patient has to choose another object, which corresponds to the same category (fruit) and to write down the corresponding word;

(3) The patient has to choose more examples of the same category (pictures, cards, real objects, or his own examples);

(4) The patient has to write down the words that correspond to the objects. It is possible to use the materialized scheme of the words, like in the previous stage, if necessary;

(5) The patient has to construct a sentence using each word and writing it down;

(6) The patient has to read the sentence with the therapist's help;

(7) The patient is asked to verify the execution of each stage of this work;

(8) The same procedure is applied to other grammar categories: adjectives, verbs, adverbs, pronouns, and so on.

Part 4: Actualization of auxiliary grammar categories. In this stage of the rehabilitation, we worked with texts. The objective was to guarantee the correct usage of articles, prepositions, and conjunctions in oral and written speech. These exercises include the following steps:

(1) The patient finds and underlines the verbs with prepositions in the texts;

(2) The patient copies the sentence;

(3) The same sentence without the prepositions is presented to the patient;

(4) The patient has to read this sentence;

(5) The patient receives a group of five prepositions in separate cards;

(6) The patient has to choose the preposition that completes the sentence correctly;

(7) The patient reads the sentence once more and verifies if the preposition is correct;

(8) The patient has to repeat the same sentence using the general scheme of the sentence (subject—noun and predicate-verb);

(9) During the work the patient is asked to verify and correct his execution constantly.

The same procedure can be done with other prepositions, articles, and conjunctions in sentences taken from different texts.

\section{Results}

The methods used in our rehabilitation program led to the reorganization of the motor sequential organization of movements and actions of the patient on material, materialized, perceptive, and verbal levels. Important positive changes were observed in the sphere of the patient's language. At the beginning of the rehabilitation process, he was able to articulate only a few words independently. The majority of these words were nouns 
(names of the patient's children, his wife's names, and some animals). The patient was able to pronounce only three verbs in their infinitive form (to eat, to live, and to drink), and three adjectives (big, little, and pretty). As an answer to any question, the patient used perseverations: yes, no, and uncle. At the end of the rehabilitation program, the patient was able to produce complete phrases and sentences with correct verb conjugations using proper grammar tenses and modes. His expressions included articles, prepositions (under, against, in, inside, for, etc.), and conjunctions used in his native language. All sentences included subject, predicate and accurate subject-verb agreement. Patient's written and oral expressions were understood by other people within and out of his family circle. Table 3 shows initial and final results of the patient's oral production.

Table 3

Oral Production Before and After Rehabilitation

\begin{tabular}{|c|c|c|}
\hline Task & Initial assessment & Final assessment \\
\hline Repetition of words & $\begin{array}{l}\text { Martha (esposa), Joaquín, hijo, perro, } \\
\text { España, casa, tienda, y, morir, } \\
\text { (Martha, Joaquín, sun, dog, Spain, home, } \\
\text { shop, and die) }\end{array}$ & $\begin{array}{l}\text { Martha, esposa, Joaquín, Cuba, España, México, } \\
\text { Puebla, barcos, papá, padre, enfermo, mama, hermano, } \\
\text { hijos, queridos, etc. } \\
\text { (Martha, wife, Joaquín, Cuba, Spain, Mexico, Puebla, } \\
\text { sheeps, father, dad, patient, mother, brother, hilaren, } \\
\text { dear) }\end{array}$ \\
\hline Repetition of phrases & $\begin{array}{l}\text { "Joaquín... Morir”, "no comer”, "Martha... } \\
\text { Martha” } \\
\text { (Joaquín... die... No } \text { eat... Martha... } \\
\text { Martha) }\end{array}$ & $\begin{array}{l}\text { "Hoy desayune, tomé jugo y comí pan”, "me ayudó a } \\
\text { bañarme Oscar y vine a clase con usted" } \\
\text { ("Today I had my breakfast and have eaten the bread. } \\
\text { Oscar helped me to bath and I came to the class with } \\
\text { you”) }\end{array}$ \\
\hline Nominative language & $\begin{array}{l}\text { Ojos, dedos, mano, lápiz, Martha, coche, } \\
\text { casa, carro }\end{array}$ & $\begin{array}{l}\text { Partes del cuerpo (cabello, cabeza, orejas, nariz, lengua, } \\
\text { dientes, etc.) } \\
\text { (Parts of the body (hair, head, eras, nose, tongue, teeth)) } \\
\text { Refacciones para auto (juntas, llaves, gato, acumulador, } \\
\text { motor, bujías, chasis, etc.); (Different parts of the car) } \\
\text { Frutas (Manzana, plátano, uvas, naranja, etc.) } \\
\text { (Different kind of fruits) } \\
\text { Prendas de vestir (pantalón, camisa, boina, camisa, zapatos, } \\
\text { etc.) (Different kinds of cloths) } \\
\text { Nombres de hijos y familiares (Names of all relatives and } \\
\text { friend) }\end{array}$ \\
\hline $\begin{array}{l}\text { Narrative language } \\
\text { and syntactic level }\end{array}$ & Inexistent & $\begin{array}{l}\text { Fui al dr. en la mañana para que me revisara el } \\
\text { corazón... es algo normal,... me siento bien... pero } \\
\text { Martha me dijo que fuéramos, nos llevó el chofer } \\
\text { (I went to the doctor in the morning in order to revise } \\
\text { my Herat... it was normal... I fell well... but Martha } \\
\text { told me that it was necessary to go and the driver took } \\
\text { us) }\end{array}$ \\
\hline
\end{tabular}

The comprehension of complex grammar structure was also achieved as a result of neuropsychological rehabilitation. The patient was able to fulfil the following instructions: "Raise your left hand", "Touch your left ear with your right hand”. These results show adequate form of usage and understanding of complex grammar by the patient.

Progressive changes in motor sequential organization were also observed in graphic activity (drawing) of the patient. In the task of copying and continuing the sequence of two elements, neither omissions of elements nor perseverations were detected in the final assessment. On the contrary, the initial assessment showed total impossibility of fulfilment of this task (see Figure 5). The motor manual task of reproduction of serial movements (dynamic praxis) lacked any mistakes in the final assessment. 
(1) Model

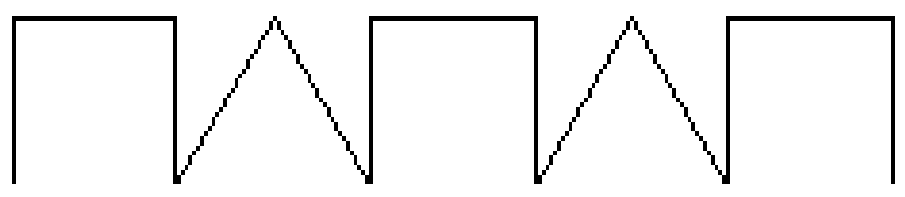

(2) Initial assessment

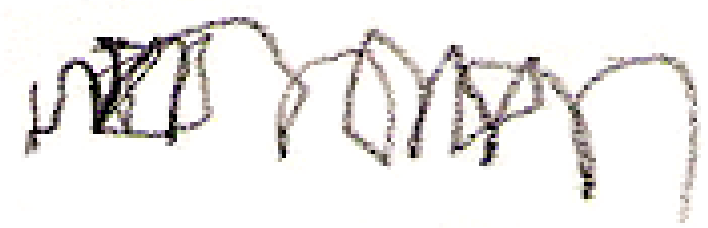

(3) Final assessment



Figure 5. The task of "copy and continuation of the sequence" by model after rehabilitation.

Important achievements were observed in the patient's drawing complex activity of the patient: the execution of the task of drawing an object following instructions, and copying of objects and free independent drawing were possible after neuropsychological rehabilitation.

Before the rehabilitation, reading and writing were processes, the patient could not carry out at all, due to the presence of severe pathological inertia and multiple perseverations. The final assessment has pointed out significant and positive results: The writing while copying, taking dictation and the writing as an independent process showed no mistakes, such as substitutions, omissions, or perseverations. The patient was able to keep a written record of his everyday activities in the form of a plan and a diary. The patient himself could read this plan to the therapist without any mistakes during the last sessions of the rehabilitation program.

In the case of mathematical operations, during the initial assessment the patient was unable to understand the meaning of this task. The obstacle, like in other tasks, was the presence of pathological inertia and severe perseverations. After the application of the program, the subject was able to fulfil basic mathematical calculations according to his educational level. It is interesting to mention that the work with numeric operations was not an objective of the rehabilitation program, the ability of solving mathematical calculations was automatically re-established as the consequence of the disappearance of perseveration and pathological inertia.

The positive results were also noticed in the fulfilment of the complex drawing. After rehabilitation, the patient was able to copy a house, a task that he could not fulfill before. The patient could also represent all the details of the model correctly. It was possible to recognize the proposed models in his execution. His only difficulty in this latter case was the representation of the second dimension in his drawings (see Figure 6). However, it is convenient to mention that normal subjects with the same educational level would also omit the second dimension in their copies (López, 2001; Quintanar, López, Solovieva, \& Sardá, 2002). The spatial depth of the parts of the objects is not commonly accessible for these subjects (Solovieva, López, \& Quintanar, 2008). 
(1) Model

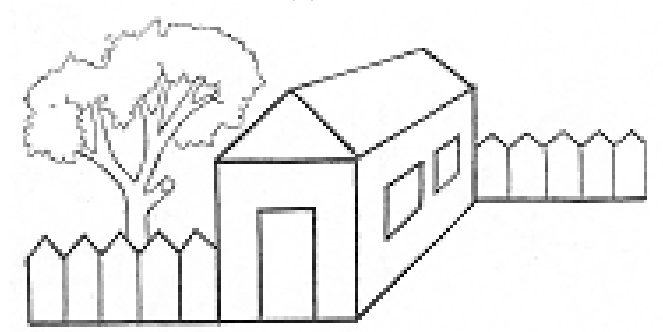

(2) Before rehabilitation

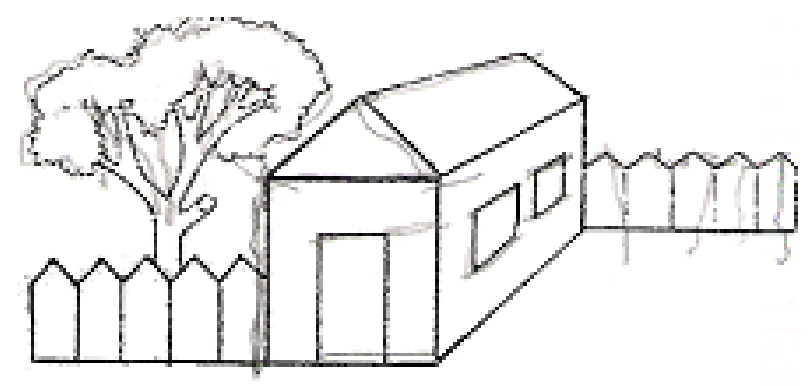

(3) After rehabilitation

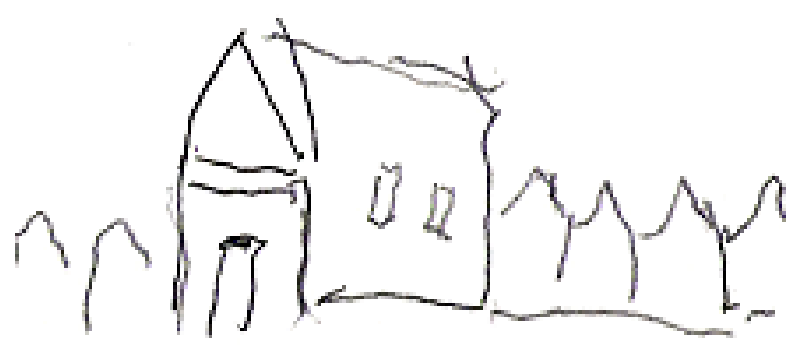

Figure 6. The task of “copy of a house” after rehabilitation.

\section{Discussion}

The rehabilitation of patients with brain injury is a field of great importance in neuropsychology. There are controversies among the authors about the possibility of function recovery, especially about the effectiveness of the rehabilitation programs (León-Carrión, Machuca, \& Domínguez, 1999; Machuca, Madrazo, Rodríguez, \& Domínguez, 2002; Machuca, León-Carrión, \& Barroso, 2006). For example, some studies have reported that aphasic patients who received therapy had a larger recovery compared with patients who did not receive therapy (Basso, Capitani, \& Vignolo, 1979; Marshall, Thompkins, \& Phillips, 1982), while in other studies no differences in the recuperation of patients with or without therapy are reported (Levita, 1978; Sarno, Silverman, \& Sands, 1970).

The recovery of functions is based on the brain plasticity, not as a spontaneous process, but a consequence of learning during the therapeutic work, focusing on the causes of the patient's difficulties.

Therefore, the interests of different health specialists in creating systematized and organized procedures that guarantee the recuperation of altered functions in patients with some kind of brain injury have increased. In favor of the necessity of designing programs directed to the rehabilitation and against the idea of spontaneous recuperation, we can mention that directed rehabilitation allows not only disinheriting 
and activating verbal comprehension and expression, but also anticipating and correcting the patient's verbal and non-verbal difficulties. In the case of the motor efferent aphasia, we can talk about agrammatism, that is to say, the single use of the nominative language, which is pointed out by authors who have had the opportunity to be in touch with subjects diagnosed with motor efferent aphasia without being treated by programs of directed neuropsychological rehabilitation (Shojor-Trotskaya, 2002). In the field of intervention projects, it could be of great use for the knowledge of the possibility of designing rehabilitation programs for adults with aphasia according to the neuropsychological, psychological, and pedagogic principles (Tsvetkova, 1985).

As it was mentioned in the introduction, the proposal of Luria and Tsvetkova (Luria \& Tsvetkova, 1977; Tsvetkova, 1988, 2000, 2001) was considered as the theoretical-methodological basis for designing our rehabilitation program. They consider that in the case of brain injury, the brain functions do not disappear, but are disorganized and weakened. In consequence, the corrective teaching must be oriented to the creation of a new functional system based on the functional elements that remain undamaged, that is to say, the restructuration of the functional system on top of new functional units. It is possible to achieve such reorganization only by including a patient in specific kinds of activities, which integrate necessary functional elements. The reorganization can be intrasystemic (reeducating the patient to fulfill tasks using more basic or higher levels inside the same functional system) or intersystemic (reeducating the patient to use other functional systems). Luria (1977) considered that the intra-systemic reorganization is the most frequent situation. In the case of this study, we dealt with an intrasystemic reorganization since our patients were reeducated to fulfill tasks using specific external supports and orientating base of action. Each time, later, we tried to step from the fulfillment of the task to a more independent level of the patient.

The qualitative analysis of the patient's syndrome allowed us to identify the factor that lays under the aphasic syndrome, which permitted designing a plan to focus not on the symptoms but on the altered factor. The results obtained from the posterior evaluation of the application of the rehabilitation program showed that the patient's performances improved significantly. The program designed according to the neuropsychological, psychological, and pedagogic principles has proved its effectiveness.

The results obtained at the end of our program proved the efficacy of proposed treatment. The correct functional reorganization achieved permitted the activation of new functional systems, which now serve as a psycho-physiological base for some complex mental processes: writing, reading, and calculating.

At the same time, our methods permitted to overcome the predominant verbal stereotypes in oral language of our patient and therefore to achieve a fluent production in all its aspects (spontaneous, repetitive, denominative, etc.). This work permitted rehabilitating the adequate use of the verb forms and other related grammar elements: diverse verb tenses, prepositions and gerunds, and consequently, the agrammatism was significantly improved.

Regarding the patient's articulate language, an adequate functional reorganization was observed. The patient achieved a better production of sentences, which were complex and accurate according to Spanish grammar, and importantly, the patient was able to integrate himself adequately to his daily life. We consider that this study is a contribution to the proposals of individualized programs for patients with brain injury, with aphasia in particular, in contrast to the more generalized proposal in the field of neuropsychological rehabilitation. 


\section{References}

Akhutina, T. (1989). Production of language: Neurolinguistic analysis of syntaxis. Moscow: Moscow State University.

Akhutina, T. (2002). Rehabilitation in cases of severe complex sensoriomotir aplasia. Spanish Journal of Neuropsychology (Revista Española de Neuropsicología), 4(2-3), 236-261.

Akhutina, T. (2002b). Neurolinguistic analysis of dynamic aphasia. Moscow: Terevinf.

Ardila, A. (2005). The aphasia. Miami, Florida: International University.

Balasubramanian, V. (2005). Dysgraphia in two forms of conduction aphasia. Brain and Cognition, 57, 8-15.

Basso, A., Capitani, E., \& Vignolo, L. (1979). Influence of rehabilitation on language skills in aphasic patients: A controlled study. Archives of Neurology, 36, 190-196.

Benson, D., \& Ardila, A. (1996). Aphasia: A clinical perspective. New York: Oxford University Press.

Cuetos, F. (1998). Assessment and rehabilitation of aphasia: Cognitive approach. Madrid: Médica Panamericana.

Cuetos, V. (2004). Assessment and rehabilitacion of aplasia. Madrid: Médica Panamericana.

Dejerine, J. (1926). Semiology of disturbances in nervous system (Semiologie des affections du systeme nerveux). París: Mouton.

Gardner, H., Zurif, E., Berry, T., \& Baker, E. (1976). Visual communication in aphasia. Neuropsychologia, 14, 275-292.

Goodglass, H. (1987). Neurolinguistics principles and aphasia therapy. In M. Meier, A. Benton, \& L. Diller (Eds.), Neuropsychological rehabilitation (pp. 315-326). New York: Plenum Press.

Goodglass, H. (1992). Diagnosis of conduction aphasia. In S. Kohn (Ed.), Hillsdale conduction aphasia. N. J.: Lawrence Erlbaum Associates.

Goodglass, H., \& Kaplan, E. (1972). The assessment of aphasia and related disorders. Philadelphia: Lea \& Febiger.

LaPointe, L. (1977). Base-10 programmed stimulation: Task specification scoring and plotting performance in aphasia therapy. Journal of Speech and Hearing Disorders, 42, 90-105.

LaPointe, L. (2005). Aphasia and related neurogenic language disorders. New York: Thieme Medical Publishers.

León-Carrión, J., Machuca, F., \& Domínguez, R. (1999). Efficiency of programs C.RE.CER for intense, integral and multidisciplinary treatment of patients with traumatic brain injury: Legal and medical values. Spanish Journal of Neuropsychology (Revista Española de neuropsicología), 1(2-3), 49-68.

Levita, E. (1978). Effects of speech therapy on aphasics: Responses to the functional communication profile. Perceptual and Motor Skills, 47, 151-154.

López, A. (2001). Evaluation of neuropsychological factors in normal population of adults of different educational levels by Breaf assessment (Master dissertation, Puebla Autonomous University).

Lorenzo, J., \& Fontán, L. (2001). Rehabilitation of cognitive disorders. Medical Journal of Uruguay (Revista Médica Uruguaya), 17, 133-139.

Luria, A. (1977). Superior cortical functions. México: Fontamara.

Luria, A. (1980). Fundaments of neurolinguistics. Barcelona: Masson.

Luria, A. (1983). Bases of neuropsychology. Moscow: Moscow State University.

Luria, A., \& Tsvetkova, L. (1977). Reeducation of language, reading and writing. Barcelona: Masson.

Machuca, F., León-Carrión, J., \& Barroso, J. (2006). Efficiency of neuropsychological rehabilitation of tardial start in functional recuperation in patients with acquired brain injury. Spanish Journal of Neuropsychology (Revista Española de Neuropsicología), 8(3-4), 81-103.

Machuca, F., Madrazo, M., Rodríguez, R., \& Domínguez, M. (2002). Integral, multidisciplinary and holistic neuropsychological rehabilitation of acquired brain injury. Journal of General and Applied Psychology (Revista de Psicología General y Aplicada), 55(1), 123-137.

Marshall, R., Thompkins, C., \& Phillips, D. (1982). Improvement in treated aphasia: Examination of selected prognostic factor. Folia Phoniatrica, 34, 305-315.

Ojeda del Pozo, N., Ezquerra-Iribarren, I., Urruticoechea-Sarriegui, J., Quemada-Ubis, J., \& Muños-Céspedes, J. (2000). Traning of social habilitéis in patients with acquired brain injury. Journal of neurology (Revista de Neurología), 8, 783-787.

Quintanar, L. (2001). Theoretical and methodological aspects of neuropsychological rehabilitation. Mexico: Puebla Autonomous University.

Quintanar, L. (2002). Theory and methotodology of neuropsychological rehabilitation. Spanish Journal of Neuropsychology (Revista Española de Neuropsicología), 4(1), 45-53. 
Quintanar, L., \& Solovieva, Yu. (2001). Methods for neuropsychological rehabilitation in adults. Mexico: Universidad Autónoma de Puebla.

Quintanar, L., \& Solovieva, Yu. (2002). Neuropsychological analysis of speech disturbances. Journal of General and Applied Psychology (Revista de Psicología General y Aplicada), 55(1), 67-87.

Quintanar, L., López, A., Solovieva, Yu., \& Sardá, N. (2002). Neuropsychological assessment of normal subject of different educational levels. Spanish Journal of Neuropsychology (Revista Española de neuropsicología), 4(2-3), 197-216.

Quintanar, L., Solovieva, Yu., \& León-Carrión, J. (2002). Diagnostic of motor efferent aplasia. Spanish Journal of Neuropsychology (Revista Española de neuropsicología), 4(4), 301-311.

Quintanar, L., Solovieva, Yu., Bonilla, M., Sánchez, A., \& Figueroa, S. (2002). Clinical and electrophysiological changes alter neuropsychological therapy in one patient with motor efferent aplasia. Latina Journal of Thinking and Language (Revista Latina de Pensamiento y Lenguaje), 5(2b), 205-222.

Quintanar, L., \& Solovieva, Yu. (2013). Breaf neuropsychological assessment for adults. Mexico: Puebla Autonomous University.

Quintanar, L., Solovieva, Yu., \& León-Carrión, J. (2011). Clinic neuropsycholiogical assessment of aplasia Puebla-Sevilla. Mexico: Puebla Autonomous University.

Sarno, M., Silverman, M., \& Sands, E. (1970). Speech therapy and language recovery in severe aphasia. Journal of Speech and Hearing Research, 13, 607-623.

Seron, X., \& Partz, M. (1993). The re-education of aphasics: Between theory and practice. In A. Holland, \& M. Forbes (Eds.), Aphasia treatment: World perspectives (pp.131-144). New York: Chapman \& Hall Press.

Shojor-Trotskaya, M. (2002). Pedagogical correction in cases of aplasia. Moscow: Institute of General Humanitarian Research.

Solovieva, Yu., Chávez, M., Pérez, A., \& Quintanar, L. (2001). Porposal for rehabilitacion of of speach comprehension in sensory aphasia. In L. Quintanar, \& Yu. Solovieva (Eds.), Methods for neuropsychological rehabilitation in adults (pp. 159-187). Mexico: Puebla Autonomous University.

Solovieva, Yu., \& Quintanar, L. (2005). Acustic mnesic aplasia: A case study. Spanish Journal of Neuropsychology (Revista Española de Neuropsicología), 7(1), 17-34.

Solovieva, Yu., \& Quintanar, L. (2011). Teaching of reading. Mexico: Trillas.

Solovieva, Yu., López, A., \& Quintanar, L. (2008). Análisis de las funciones espaciales en adultos de diferentes niveles educativos. Revista de Ciencias Clínicas, 9, 1-13.

Tsvetkova, L. (1985). Rehabilitation of patients with aphasia. Moscow: Moscow State University.

Tsvetkova, L. (1988). Aphasia and re-education. Moscow: Education.

Tsvetkova, L. (1995). Brain and intellect. Moscow: Ilustration.

Tsvetkova, L. (2000). Introduction to neuropsychology and rehabilitation. Moscow: Moscow Psychological and Social Institute.

Tsvetkova, L. (2001). Neuropsychology and aphasia: New approximation. Moscow: Moscow Psychological and Social Institute.

Tsvetkova, L., \& Torchua, N. (1997). Aphasia and perception. Moscow: Moscow Academy of Pedagogical and Social Sciences.

Wilson, B. (2000). Compensating for cognitive deficits following brain injury. Neuropsychological Review, 10, $233-243$.

Xomskaya, E. (2002). The problem of catros in neuropsychology. Spanish Journal of Neuropsychology (Revista Española de Neuropsicología), 4(2-3), 151-167. 